\title{
Características físicas e sensoriais de biscoitos com farinha de soja e farelo de aveia
}

\author{
Physical and sensorial characteristics of cookies containing deffated soy flour and oat bran
}

\author{
Mirian Cristina MARETI ${ }^{1}$, Maria Victória Eiras GROSSMANN ${ }^{2 \star}$, Marta de Toledo BENASSI ${ }^{1}$
}

\begin{abstract}
Resumo
A crescente demanda por alimentos ricos em ingredientes funcionais é um incentivo ao desenvolvimento e industrialização desses produtos. O objetivo deste trabalho foi desenvolver formulação de biscoito com potenciais propriedades hipocolesterolêmicas, pela combinação de diferentes teores de Farinha Desengordurada de Soja (FDS) e de Farelo de Aveia (FA), em substituição parcial à farinha de trigo. Além desses dois ingredientes, também foi estudado o efeito de maltodextrina, como possível melhorador de textura. Para a realização do experimento, foi empregado planejamento de misturas com três componentes, com restrições para os níveis mínimo e máximo. As três variáveis afetaram significativamente a dureza e o diâmetro dos biscoitos, que aumentaram com teores maiores de maltodextrina. As massas que continham maiores teores de FDS apresentaram-se mais secas e duras, o que pode ter afetado a expansão. Na análise descritiva de perfil livre, comparandose três amostras com diferentes durezas, verificou-se que aquela com maior teor de FDS diferenciou-se daquelas com maior teor de FA e com teores iguais de FDS e FA, sendo caracterizada como mais dura, de cor mais escura e apresentando sabor mais característico de biscoito integral/cereal. No entanto, não se observou diferença na aceitação entre as três amostras. Foi possível substituir 70,7\% da farinha de trigo de uma formulação original, por misturas de FA e FDS, obtendo-se produtos com boa aceitação.
\end{abstract}

Palavras-chave: alimentos funcionais; textura; perfil livre; panificação.

\begin{abstract}
The increasing demand for foods containing functional ingredients promotes the development and industrialization of these products. The objective of this work was to develop biscuits with potential hypocholesterolemic properties by combining Defatted Soy Flour (DSF) and Oat Bran (OB) as partial substitution of wheat flour. The action of maltodextrins as potential texture improver was also studied, and the mixture design was employed to conduct the experiment. Biscuits hardness and diameter were significantly affected by the three studied variables, increasing with higher levels of maltodextrins. The dough with higher levels of DSF seems to be harder and dry which might have affected the spread. Comparing three samples with different hardness in the descriptive analysis of free choice profile, it was observed that those with higher level of DSF proved different from those with higher level of OB or with similar levels of the two ingredients. Therefore, it was characterized as the hardest darkest, and having the most typical flavor of whole grain biscuit/cereal. However, the three samples did not differ in acceptability. It was possible to substitute $70.7 \%$ of wheat flour of an original formulation for blends of DSF and OB obtaining products with good acceptability.
\end{abstract}

Keywords: functional foods; texture; free choice profile; baking.

\section{Introdução}

A crescente demanda por alimentos ricos em fibras está associada com diversos resultados benéficos para o organismo humano. Alterações nas funções gastrointestinais, na sensação de saciedade, aumento da massa fecal - diminuindo assim o desconforto causado pelo sintoma de constipação intestinal -, redução de risco de algumas doenças crônicas (como úlcera péptica, doença de Crohn e colite ulcerosa), redução dos níveis de colesterol e o fato comprovado de que dietas ricas em fibras reduzem o risco de doenças cardiovasculares, são alguns desses benefícios (MILLER et al., 1994; LÓPEZ et al., 1997; BROWN et al., 1999).

Diversos estudos têm mostrado que o consumo de fibras solúveis, como as $\beta$-glucanas em produtos de aveia, reduz o colesterol total sanguíneo e as concentrações de LDLcolesterol (RIPSIN et al., 1992; ANDERSON; BRIDGES, 1993;
ROMERO et al., 1998; BROWN et al., 1999; KARMALLY et al., 2005).

Da mesma forma, também já foi comprovado o efeito da proteína de soja na diminuição dos níveis de colesterol (ANDERSON; JOHNSTONE; COOK-NEWELL, 1995; PAZZUCCONI; DELLA MURA; SIRTORI, 1997; NAGATA et al., 1998; WONG et al., 1998; JENKINS et al., 2000).

Muitos produtos de confeitaria são usados como veículos para incorporação de nutrientes e compostos bioativos. Entre estes, os biscoitos se destacam pelas facilidades tecnológicas que propiciam ao comportarem grande variedade de ingredientes $\mathrm{e}$ formulações, assim como também grande flexibilidade quanto a matérias-primas e características do produto final.

Recebido para publicação em 5/8/2008

Aceito para publicação em 31/10/2009 (003562)

${ }^{1}$ Departamento de Tecnologia de Alimentos e Medicamentos, Universidade Estadual de Londrina - UEL, Londrina - PR, Brasil

${ }^{2}$ Departamento de Ciência e Tecnologia de Alimentos, Universidade Estadual de Londrina - UEL, CP 6001, CEP 86051-970, Londrina - PR, Brasil, E-mail: victoria@uel.br

${ }^{*}$ A quem a correspondência deve ser enviada 
Embora não constituam um alimento básico como o pão, os biscoitos são aceitos e consumidos por pessoas de qualquer idade e sua longa vida de prateleira permite que sejam produzidos em grande quantidade e largamente distribuídos (EL-DASH; GERMANI, 1994).

Porém, na substituição parcial da farinha de trigo por fontes proteicas e de fibras, é possível que ocorram problemas tecnológicos. Estes componentes ocasionam aumento na absorção de água, provocado pelo aporte de grupos hidrofílicos (SUDHA; VETRIMANI; LEELAVATHI, 2007). Assim, é necessário aumentar a quantidade de água na formulação, para que a massa não fique seca e quebradiça (EL-DASH; GERMANI, 1994). Também são afetadas as propriedades de mistura da massa (tempo de desenvolvimento, estabilidade, tolerância à mistura), sua elasticidade e extensibilidade e as características do produto final (volume, cor, umidade e dureza) (SUDHA; VETRIMANI; LEELAVATHI, 2007).

O objetivo deste trabalho foi desenvolver formulações de biscoitos com potenciais propriedades hipocolesterolêmicas pela combinação de farinha desengordurada de soja e farelo de aveia em substituição parcial à farinha de trigo, avaliando as características físico-químicas e sensoriais do biscoito desenvolvido.

\section{Material e métodos}

$\mathrm{Na}$ formulação dos biscoitos, utilizou-se farinha desengordurada de soja (FDS) $(50,92 \%$ de proteína, 0,99\% de lipídios e $31,59 \%$ de fibra alimentar) fornecida pela Caramuru Alimentos (Apucarana - PR) e Farelo de Aveia (FA) (23,38\% de proteína, 7,14\% de lipídios e $26,93 \%$ de fibra alimentar) fornecido pela SL Cereais e Alimentos Ltda. (Mauá da Serra - PR). Outros ingredientes como, gordura vegetal sem sal, açúcar, bicarbonato de sódio, lecitina de soja, maltodextrina, ovo em pó e farinha de trigo especial ( $14,71 \%$ de proteína, $0,80 \%$ de lipídios, $2,31 \%$ de fibra alimentar, tenacidade $(\mathrm{P})=110 \mathrm{~mm}$, extensibilidade $(\mathrm{L})=50,5 \mathrm{~mm}$ e força de glúten $\left.(\mathrm{W})=219,5 \times 10^{-4} \mathrm{~J}\right)$, foram adquiridos no comércio local.

\subsection{Formulação}

O experimento foi executado empregando-se a formulação apresentada na Tabela 1, resultante da substituição de grande parte $(70,7 \%)$ da farinha de trigo de uma formulação base, por uma mistura de FDS, FA e maltodextrina. Estes 3 últimos ingredientes foram selecionados como variáveis, em testes preliminares, que mostraram a sua significância nas características de dureza e expansão dos biscoitos. A proporção entre eles, dentro da mistura ternária, variou, em cada ensaio, de acordo com o planejamento experimental, enquanto os demais componentes da fórmula foram mantidos constantes.

O processo de preparação seguiu o macrométodo da AACC 10-50D (AMERICAN..., 1990). A massa foi processada em batedeira planetária da marca Arno, misturando-se inicialmente a margarina e o açúcar, em velocidade baixa, por 30 segundos. Em seguida, adicionaram-se os demais ingredientes sólidos e a água, misturados em velocidade média, por dois minutos. Obtida a massa, esta foi estendida com rolo até a espessura de $5 \mathrm{~mm}$ e moldada com o auxílio de forma circular de $4 \mathrm{~cm}$ de diâmetro. Os biscoitos foram assados a 180 $\pm 2{ }^{\circ} \mathrm{C}$ por 25 minutos.

Após a saída do forno, os biscoitos foram resfriados à temperatura ambiente e acondicionados em sacos de polipropileno biorientado laminado. Cada formulação produziu em média 18 biscoitos, sendo acondicionados em pacotes com peso médio total de $90 \mathrm{~g}$, os quais foram selados em seladora da marca Selovac (São Paulo - SP) e conservados até o momento das análises.

\subsection{Análises}

A determinação de dureza dos biscoitos foi realizada em analisador de textura TA-XT2i (Texture Technologies Corp., Scarsdale, NY) com o software XTRAD Texture Expert para a análise dos dados. Cada amostra de biscoito foi disposta horizontalmente numa plataforma e cortada ao meio com "probe" tipo faca HDP/BSK, blade set with knife, com velocidades pré-teste, teste e pós-teste de $5,0 \mathrm{~mm} / \mathrm{s}$, força do trigger de $0,20 \mathrm{Ne} 5,0 \mathrm{~mm}$ de distância, registrando-se a força de ruptura ou de quebra (dureza). Cada biscoito apresentava em média $10 \mathrm{~mm}$ de altura e $40 \mathrm{~mm}$ de diâmetro. Foram realizadas seis determinações em cada formulação, em amostras selecionadas de forma aleatória.

Foi calculado o fator de expansão (diâmetro/espessura), pela medida de diâmetro e de espessura de seis biscoitos provenientes de uma mesma fornada e amostrados de forma aleatória, sendo estes determinados com paquímetro (Mitutoyo- Modelo 530101, Tókio, Japão). Contudo, os resultados de fator de expansão variaram pouco entre as formulações e não permitiram uma modelagem, sendo então o diâmetro dos biscoitos considerado como resposta.

Visando possibilitar uma comparação, biscoitos de marcas comerciais, que continham farinha de soja ou farelo de aveia em sua composição, foram também avaliados quanto à dureza.

\subsection{Análise sensorial}

A partir dos resultados das análises, foram selecionadas três formulações (F3, F6 e F9) que apresentavam características diferenciadas quanto à dureza instrumental, para avaliação sensorial.

Tabela 1. Formulação dos biscoitos.

\begin{tabular}{lcc}
\hline \multicolumn{1}{c}{ Ingredientes } & Peso $(\mathrm{g})$ & $(\%)^{*}$ \\
\hline Farinha de trigo & 60,0 & 100,0 \\
(FDS + FA + Maltodextrina) ${ }^{* *}$ & 145,0 & 241,7 \\
Açúcar cristal & 75,0 & 125,0 \\
Margarina & 22,0 & 36,7 \\
Fermento em pó químico & 7,0 & 11,7 \\
Lecitina de soja & 0,5 & 0,8 \\
Ovo em pó & 12,0 & 20,0 \\
Água & 75,0 & 125,0 \\
\hline
\end{tabular}

${ }^{*}$ Em relação à farinha de trigo; FDS = farinha desengordurada de soja; FA = farelo de aveia; $e^{* *}$ a proporção entre estes ingredientes, variou conforme o planejamento experimental. 
As análises foram iniciadas 48 horas após a elaboração das amostras. Os biscoitos foram dispostos em prato de fundo branco e codificados com números de três dígitos. A ordem de apresentação foi aleatorizada e entre as provas foi oferecida água. Os testes foram realizados em cabines individuais com luz branca.

Para seleção e caracterização das equipes, foi entregue um questionário de coleta de dados de faixa etária, escolaridade e hábitos de consumo referentes a produtos de soja e aveia, bem como o interesse em participar do teste.

\section{Análise descritiva de perfil livre}

Foram empregados 14 provadores não treinados. A equipe foi composta por alunos (73\%), jovens (93\% com até 35 anos), com alta escolaridade ( $93 \%$ com $3^{\circ}$ grau completo) e consumidores frequentes ou moderados de biscoitos/bolachas. Todos afirmaram gostar do sabor aveia e 79\% do sabor soja, $93 \%$ afirmaram consumir frequente ou moderadamente alimentos com aveia e $50 \%$ com soja.

Para levantamento dos atributos, foi utilizado o método de rede (MOSKOWITZ, 1983), em duas sessões, sendo que, em cada sessão, foi apresentado um par de amostras para que os provadores apontassem as similaridades e diferenças. Os pares foram apresentados de maneira a levantar o maior número de atributos possível, com relação à aparência, aroma, sabor e textura. Os atributos desenvolvidos pela equipe foram diferenciados e o número levantado variou de cinco a dez, com uma média de sete. Após o levantamento de atributos, foram montadas, com cada provador, a ficha e a lista de definição dos atributos e fez-se uma sessão simulando a apresentação real, para que os provadores alterassem, se necessário, as definições, termos e extremos de escala.

\section{Análise de aceitação}

A aceitação foi avaliada com a participação de 50 provadores potenciais do produto: $94 \%$ dos provadores consumiam moderada ou frequentemente biscoitos e bolachas. Na equipe, $82 \%$ dos provadores apresentaram idade até 35 anos, $80 \%$ eram alunos e a maioria (94\%) possuía nível de escolaridade igual ou superior ao $3^{\circ}$ grau. Todos afirmaram gostar dos sabores soja e aveia, sendo que $46 \%$ dos provadores consumiam moderadamente alimentos com aveia e $38 \%$ alimentos com soja. O consumo frequente destes alimentos foi citado por $12 \%$ dos provadores.

Foi utilizada escala hedônica estruturada de nove pontos com termos verbais no meio e nos extremos, sendo 1 , atribuído para desgostar muitíssimo e 9, para gostar muitíssimo (OLIVEIRA et al., 2004).

\subsection{Planejamento experimental e análise estatística}

\section{Estudo das características físicas dos biscoitos}

Foi empregado planejamento para misturas com três componentes, com restrições para os níveis mínimos e máximos
(BARROS NETO; SCARMINIO; BRUNS, 2003). Esses níveis mínimos e máximos foram: 27,6 e 62,1; 27,6 e 62,1; 1,4 e 10,3, para FDS, FA e maltodextrina, respectivamente.

Em função das restrições, o planejamento foi ajustado, reduzindo a escala original, mas garantindo que a correta distribuição dos experimentos fosse obedecida. Isto foi feito por meio dos pseudocomponentes, que são combinações dos componentes originais, utilizadas para redefinir as coordenadas de misturas em relação ao espaço experimental a ser estudado (BARROS NETO; SCARMINIO; BRUNS, 2003). O cálculo dos pseudocomponentes foi realizado de acordo com as Equações 1 a 3:

$$
\begin{aligned}
& X_{F D S}=\frac{C_{F D S}-0,276}{0,434} \\
& X_{F A}=\frac{C_{F A}-0,276}{0,434} \\
& X_{\text {Maltodextrina }}=\frac{C_{\text {Maltodextrina }}-0,014}{0,434}
\end{aligned}
$$

em que: $\mathrm{X}_{\mathrm{i}}=$ valor do pseudocomponente; $\mathrm{e}_{\mathrm{i}}=$ concentração real do componente.

O planejamento experimental está apresentado na Tabela 2. Foram introduzidas duas repetições do ensaio 9 (formulações 10 e 11) para o cálculo do erro puro e ajuste dos modelos. Os ensaios foram realizados ao acaso. Após a execução do experimento e a coleta de dados, fez-se o ajuste de uma equação polinomial (modelo canônico de Scheffé) para cada resposta analisada, estimando-se os respectivos coeficientes.

As propriedades analisadas em cada ensaio foram dureza e fator de expansão dos biscoitos, sendo que os resultados de dureza foram transformados para a função logarítmica, para possibilitar a modelagem.

Tabela 2. Planejamento experimental para estudo das propriedades

\begin{tabular}{|c|c|c|c|c|c|c|}
\hline \multirow[t]{3}{*}{ Ensaio } & \multicolumn{6}{|c|}{ Proporção dos ingredientes na mistura ternária ${ }^{1}$} \\
\hline & \multicolumn{3}{|c|}{ Em concentrações reais } & \multicolumn{3}{|c|}{ Em pseudocomponentes } \\
\hline & $\begin{array}{l}\text { FDS } \\
\left(c_{1}\right)\end{array}$ & $\begin{array}{l}\text { FA } \\
\left(c_{2}\right)\end{array}$ & $\begin{array}{c}\text { Malto } \\
\text { dextrina }\left(\mathrm{c}_{3}\right)\end{array}$ & $\begin{array}{l}\text { FDS } \\
\left(\mathrm{X}_{1}\right)\end{array}$ & $\begin{array}{l}\mathrm{FA} \\
\left(\mathrm{X}_{2}\right)\end{array}$ & $\begin{array}{c}\text { Malto } \\
\text { dextrina }\left(\mathrm{X}_{3}\right)\end{array}$ \\
\hline 1 & 0,621 & 0,276 & 0,103 & 0,79 & 0,00 & 0,21 \\
\hline 2 & 0,276 & 0,621 & 0,103 & 0,00 & 0,79 & 0,21 \\
\hline 3 & 0,621 & 0,365 & 0,014 & 0,79 & 0,21 & 0,00 \\
\hline 4 & 0,365 & 0,621 & 0,014 & 0,21 & 0,79 & 0,00 \\
\hline 5 & 0,621 & 0,321 & 0,059 & 0,79 & 0,10 & 0,10 \\
\hline 6 & 0,321 & 0,621 & 0,059 & 0,10 & 0,79 & 0,10 \\
\hline 7 & 0,493 & 0,493 & 0,014 & 0,50 & 0,50 & 0,00 \\
\hline 8 & 0,449 & 0,449 & 0,103 & 0,40 & 0,40 & 0,21 \\
\hline 9 & 0,471 & 0,471 & 0,059 & 0,45 & 0,45 & 0,10 \\
\hline 10 & 0,471 & 0,471 & 0,059 & 0,45 & 0,45 & 0,10 \\
\hline 11 & 0,471 & 0,471 & 0,059 & 0,45 & 0,45 & 0,10 \\
\hline
\end{tabular}
dos biscoitos, em proporções reais dos ingredientes na mistura e em pseudocomponentes.

Fonte: Statsoft (STATISTICA..., 1995); ${ }^{1} \mathrm{X} 1+\mathrm{X} 2+\mathrm{X} 3=1$ ou $100 \%$. 
Os modelos matemáticos ajustados a cada resposta foram submetidos à análise de variância (ANOVA) para determinar a significância do modelo de regressão em nível de 5\% (teste F) e o coeficiente de determinação ajustado ( $\mathrm{R}^{2}$ ajustado). Para estudo da significância dos efeitos individuais na variável resposta, as variáveis dependentes foram ajustadas em nível de 5\% ( $\mathrm{p} \leq 0,05)$. Para obtenção do planejamento experimental, análise dos dados e construção de gráficos, utilizou-se o programa Statistica versão 5.0 (STATISTICA..., 1995).

\section{Análise sensorial}

No Perfil Livre, empregou-se planejamento de blocos completos balanceado para três amostras. Foram realizadas três sessões, nas quais cada provador avaliou um bloco (três) amostras por sessão, de forma que o delineamento inteiro foi apresentado uma vez, com total de 3 provas por amostra para cada provador. Para análise dos dados, utilizou-se Análise Procrustes Generalizada empregando-se o programa Senstools Versão 2.3 (OP\&P PRODUCT RESEARCH, 1998). Para caracterização e discriminação das amostras, consideraram-se os atributos que apresentaram maiores correlações para cada provador $(\geq|0,5|)$, para efeito de interpretação da configuração de consenso.

$\mathrm{Na}$ análise de aceitação, o planejamento foi o de blocos completos e os resultados foram analisados por ANOVA, considerando-se como causa de variação amostra e provadores, e teste de média (Tukey, $\mathrm{p} \leq 0,05$ ), empregando-se o programa Statistica 5.0 (STATISTICA..., 1995).

\section{Resultados e discussão}

\subsection{Características físicas}

A Tabela 3 apresenta os resultados dos coeficientes de regressão e da análise de variância dos modelos matemáticos ajustados às variáveis resposta dureza e diâmetro dos biscoitos.

Os três ingredientes estudados foram significativos para a dureza dos biscoitos. O modelo ajustado foi significativo $(\mathrm{p}=0,006)$ e o coeficiente de determinação ajustado foi de $81 \%$. Os coeficientes negativos das interações entre FDS e maltodextrina $\left(\beta_{13}\right)$ e também da interação ternária indicaram uma ação antagônica, contribuindo para a diminuição da dureza do biscoito.

Os resultados variaram de 84,99 a 217,83 N (Figura 1), que correspondem aos valores de log de 1,89 a 2,32, observando-se que os menores valores ocorreram na região central do gráfico, aumentando quando se aumentaram os teores de maltodextrina, FA ou FDS.

O emprego da maltodextrina como ingrediente é recomendado para diminuir a dureza de biscoitos, porém, no presente estudo, o efeito foi contrário, talvez porque o teor usado tenha sido insuficiente para causar o efeito desejado.

Nas análises realizadas em biscoitos comerciais, cuja composição continha farinha de soja ou farelo de aveia, podem-se observar valores de dureza entre 24,67 e 40,53 N. Esta comparação permitiu classificar os biscoitos desenvolvidos como bastante duros e as diferenças nesta propriedade podem estar relacionadas com os níveis de substituição da farinha de trigo por farinha de soja ou por farelo de aveia (que nos produtos comerciais podem ser menores) e, também, com os demais ingredientes e suas proporções. McWaters et al. (2003) atribuíram a textura mais dura em biscoitos ao aumento do conteúdo de proteína e sua interação durante o desenvolvimento da massa e seu assamento.

Em relação aos efeitos da FA, Sudha, Vetrimani e Leelavathi (2007) observaram que a dureza de biscoitos aumentou com o aumento do teor de 10 para $40 \%$, sendo este mesmo comportamento verificado com fibras de outras fontes. Isto

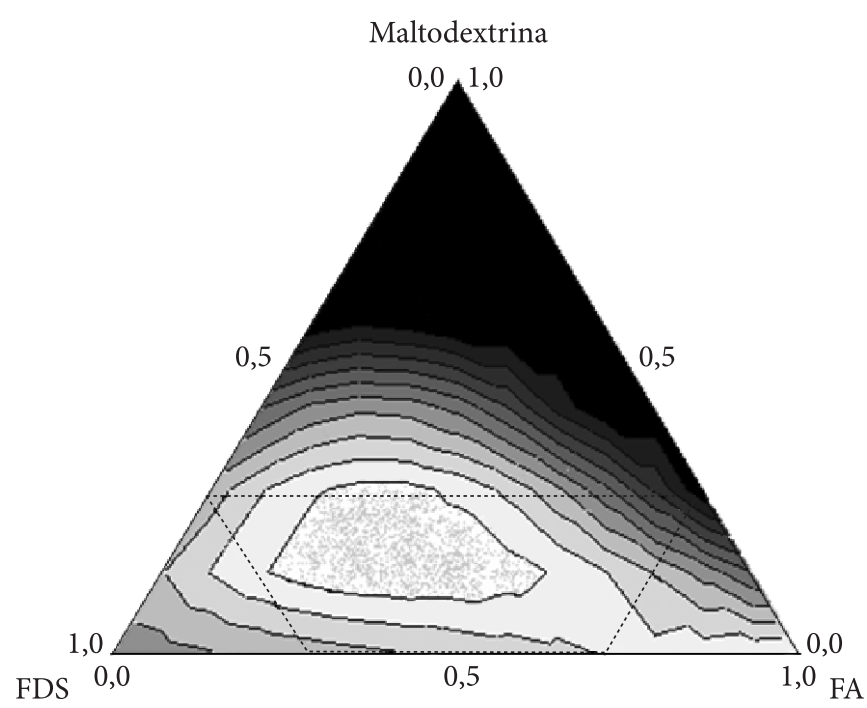

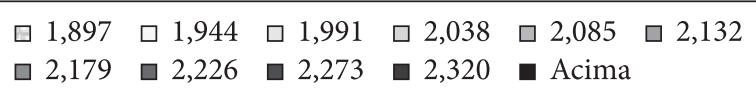

Figura 1. Dureza do biscoito em função dos teores de FDS, FA e maltodextrina (em pseudocomponentes). A linha pontilhada delimita a área experimental.

Tabela 3. Coeficientes de regressão e análise de variância dos modelos matemáticos ajustados às variáveis resposta.

\begin{tabular}{|c|c|c|}
\hline & \multicolumn{2}{|c|}{ Variáveis resposta } \\
\hline & $Y_{1}$ & $Y_{2}$ \\
\hline$\beta_{1}$ & $2,068^{\star}$ & $4,171^{\star}$ \\
\hline$\beta_{2}$ & $1,891^{*}$ & $4,166^{*}$ \\
\hline$\beta_{3}$ & $3,586^{*}$ & $13,843^{*}$ \\
\hline$\beta_{12}$ & - & - \\
\hline$\beta_{13}$ & $-2,382^{*}$ & $-13,369^{*}$ \\
\hline$\beta_{23}$ & - & $-11,223^{*}$ \\
\hline$\beta_{123}$ & $-7,906^{*}$ & $7,384^{*}$ \\
\hline Significância do modelo (p) & $0,006^{*}$ & $0,015^{*}$ \\
\hline Falta de ajuste do modelo (p) & 0,09 & 0,44 \\
\hline $\mathrm{R}^{2}$ ajustado & 0,81 & 0,80 \\
\hline
\end{tabular}


também foi observado por Uysal et al. (2007) com farelo e fibra de trigo.

Quanto ao diâmetro dos biscoitos, as três variáveis foram significativas (Tabela 2), assim como também as interações $\beta_{13}$, $\beta_{23}$ e $\beta_{123}$. Os coeficientes das interações binárias foram negativos, indicando o efeito antagônico. De acordo com a análise de variância, o modelo apresentou-se significativo $(\mathrm{p}=0,02)$, com coeficiente de determinação ajustado de $80 \%$.

Os valores do diâmetro dos biscoitos variaram de 4,15 a $4,60 \mathrm{~cm}$ (Figura 2), sendo que os menores valores encontramse na região onde há maior teor de FDS, enquanto o teor de FA teve pouca influência.

Durante a fase de modelagem da massa para a produção dos biscoitos foi observado que formulações com teores de FDS mais elevado apresentaram massas mais duras (ou firmes), enquanto que, em formulações com teores mais elevados de FA, as massas apresentaram-se mais moles. Desta forma, tais características afetaram diretamente a modelagem das massas e, provavelmente, o diâmetro dos biscoitos.

Kissel, Prentice e Yamazaki (1975) afirmaram que o fenômeno de expansão de biscoitos é primariamente físico e controlado pela capacidade dos componentes de absorver água. Assim, o acréscimo de componentes que possuem maior capacidade de reter água do que a farinha de trigo (como é o caso da FDS e do FA) resulta em uma competição pela água livre presente na massa do biscoito, limitando a taxa de expansão. Estudo anterior constatou que na utilização de farinhas proteicas, como a de soja, há uma tendência em tornar a massa mais forte, podendo prejudicar sua extensibilidade em níveis de substituição mais elevados (EL-DASH; GERMANI, 1994).

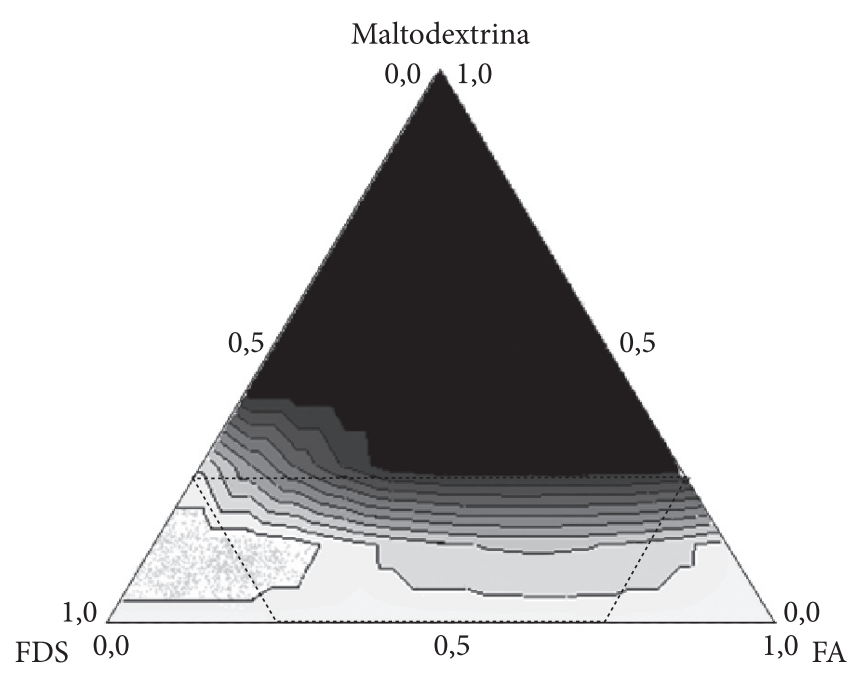

$$
\begin{aligned}
& \square 4,150 \quad \square 4,200 \quad \square 4,250 \quad \square 4,301 \quad \square 4,351 \quad \square 4,401 \\
& \square 4,452 \quad \square 4,502 \quad \square 4,553 \quad \square 4,603 \quad \square \text { Acima }
\end{aligned}
$$

Figura 2. Diâmetro dos biscoitos em função dos teores de FDS, FA e maltodextrina (em pseudocomponentes). A linha pontilhada delimita a área experimental.
Sudha, Vetrimani e Leelavathi (2007) observaram que o farelo de aveia aumentou o diâmetro de biscoitos, quando o teor passou de $10 \%$ para $40 \%$. Outras fontes de fibra (farelo de trigo, farelo de arroz), porém, ocasionaram efeito contrário.

\subsection{Análise sensorial}

Para a avaliação sensorial, foram selecionadas três formulações (F3, F6 e F9) que além de apresentarem características diferenciadas quanto à formulação, diferiam quanto à dureza instrumental. Em sua composição, as formulações F3 e F6 apresentavam maiores teores de FDS e $\mathrm{FA}$, respectivamente, enquanto que a F9, apresentava estes dois componentes em proporções iguais. Com relação à dureza, as formulações F3, F6 e F9 apresentaram valores de 104,61; 92,07 e 77,77 N, respectivamente.

No Perfil Livre, a análise dos dados foi feita empregando-se as duas primeiras dimensões, e o total da variância explicada foi de 30\%. Na Figura 3, pode-se observar a configuração consenso utilizando-se atributos de aparência, aroma, sabor e textura. A amostra F3, com mais soja, foi caracterizada como sendo diferenciada das amostras F6 e F9.

A dimensão 1, responsável por $17 \%$ da variância, foi correlacionada com a cor positivamente; com os atributos de textura, maciez negativamente; e com dureza positivamente. A dimensão 2 , responsável por $13 \%$ da variância, foi correlacionada positivamente com atributo de sabor característico (de biscoito integral, de biscoito, de cereal) e negativamente com o sabor doce/adocicado. Os atributos de aroma contribuíram pouco para a diferenciação.

A amostra F3 foi caracterizada como a mais dura, com cor mais escura (amarelada, bege, caramelo, assado, tostado, marrom, corado) e com sabor mais característico de biscoito integral/ cereal. As amostras F6 e F9 foram caracterizadas como sendo semelhantes: mais claras, macias e doces/adocicadas que a F3.

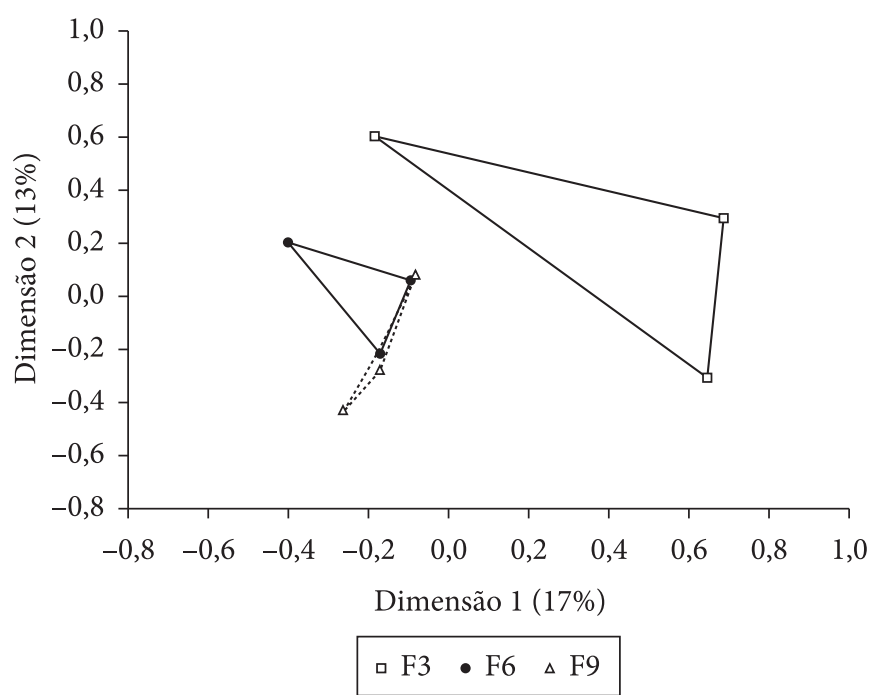

Figura 3. Configuração consenso das amostras para a equipe de Perfil Livre. F3 = 79\% FDS, $21 \%$ FA, $0 \%$ maltodextrina; F6 = 10\% FDS, 79\% FA, $10 \%$ maltodextrina; F9 = 45\% FDS, 45\% FA, 10\% maltodextrina. 
Vários atributos levantados pela equipe para a homogeneidade da aparência (presença/ausência de grânulos, rachaduras e ranhuras) e aroma característico (associado com bolacha caseira, biscoito integral, soja, aveia, de cereal) não foram utilizados para discriminação das amostras, mas são importantes para caracterização dos produtos. Assim, todas as amostras apresentaram a aparência com grânulos/rachaduras e o aroma característico.

Com relação à aceitação, não foram observadas diferenças significativas entre as notas médias 7,3; 7,0; e 7,0, atribuídas às formulações 3,6 e 9, respectivamente. Este resultado é extremamente interessante porque torna possível escolher a formulação com melhores características tecnológicas e/ou de custo para produção em escala industrial, embora o efeito da qualidade tecnológica da farinha de trigo não tenha sido estudada.

\section{Conclusões}

Foi possível desenvolver formulações de biscoitos que obtiveram boa aceitabilidade pela substituição de 70,7\% da farinha de trigo de uma formulação original por misturas de farinha de soja desengordurada e farelo de aveia, em diferentes proporções. Esta aceitabilidade decorreu da proporção adequada entre os ingredientes, evitando grande impacto negativo nas características físicas e sensoriais.

Mesmo sendo a dureza uma das características mais importantes para o consumidor, amostras selecionadas com diferentes durezas tiveram a mesma aceitabilidade. Assim, é possível escolher a formulação com melhores características de processamento para a produção em escala industrial, uma vez que foram observadas massas mais moles e massas mais duras com relação à modelagem.

Foi possível, através da análise descritiva de Perfil Livre, realizar a caracterização das amostras, ressaltando que estas apresentavam pouca diferenciação com relação aos atributos estudados, com exceção apenas daquela com maior teor de farinha de soja, caracterizada como mais dura, de cor mais escura e apresentando sabor mais característico de biscoito integral/cereal.

\section{Agradecimentos}

Os autores agradecem à CAPES a bolsa concedida.

\section{Referências bibliográficas}

AMERICAN ASSOCIATION OF CEREAL CHEMISTS. Aproved methods of the American Association of Cereal Chemists. 8. ed. Saint Paul: AACC, 1990.

ANDERSON, J. W.; BRIDGES, S. R. Hipocholesterolemic effects of oat bran in humans. In: WOOD, P. J. (Ed.). Oat Bran. Saint Paul: American Association of Cereal Chemists, 1993. p. 139-157.

ANDERSON, J. W.; JOHNSTONE, B. M.; COOK-NEWELL, M. E. Meta-analysis of the effects of soy protein in-take on serum lipids. New England Journal Medicine, v. 333, p. 276-282, 1995.

BARROS NETO, B.; SCARMINIO, I. S.; BRUNS, R. E. Como modelar misturas. In: Como fazer experimentos: pesquisa e desenvolvimento na ciência e na indústria. 2. ed. Campinas: UNICAMP, 2003. p. 301-347.

BROWN, L. et al. Cholesterol-lowering effects of dietary fiber: a metaanalysis. American Journal Clinical Nutrition, v. 69, p. 30-42, 1999.

EL-DASH, A.; GERMANI, R. (Eds.). Tecnologia de farinhas mistas: uso de farinhas mistas na produção de biscoitos. Brasília: EMBRAPA-SPI, 1994. v. 6, 47 p.

JENKINS, D. J. A. et al. Effect of soy-based breakfast cereal on blood lipids and oxidized low-density lipoprotein. Metabolism, v. 49, n. 11, p. 1496-1500, 2000.

KARMALLY, W. et al. Cholesterol-lowering benefits of oat-containing cereal in Hispanic Americans. Journal of the American Dietetic Association, v. 105, n. 6, p. 967-970, 2005.

KISSEL, L. T.; PRENTICE, N.; YAMAZAKI, W. T. Protein enrichment of cookie flours with wheat gluten and soy flour derivatives. Cereal Chemistry, v. 52, n. 6, p. 638-649, 1975.

LÓPEZ, G. et al. Propiedades funcionales de la fibra dietética. Mecanismos de acción en el tracto gastrointestinal. Archivo Latinoamericano de Nutricion, v. 47, n. 3, p. 203-207, 1997.

MCWATTERS, K. H. et al. Physical and sensory characteristics of sugar cookies containing a mixture of fonio (Digitaria exilis) and cowpea (Vigina unguiculata) flours. International Journal of Food Science and Technology, v. 38, n. 4, p. 403-410, 2003.

MILLER, W. C. et al. Dietary fat, sugar, and fiber predict body fat content. Journal of the American Dietetic Association, v. 94, n. 6, p. 612-615, 1994.

MOSKOWITZ, H. R. Product testing and sensory evaluation of foods: marketing and R\&D Approaches. Food and Nutrition Press, p. 605, 1983.

NAGATA, C. et al. Decreased serum total cholesterol concentration is associated with high intake of soy products in Japanese men and women. Journal Nutrition, v. 128, n. 2, p. 209-213, 1998.

OLIVEIRA, A. P. V. et al. Aceitação de sobremesas lácteas dietéticas e formuladas com açúcar: teste afetivo e mapa de preferência interno. Ciência e Tecnologia de Alimentos, v. 24, n. 4, p. 627-633, 2004.

OP\&P PRODUCT RESEARCH. Senstools Versão 2.3. Utrecht: OP\&P Product Research, 1998. CD room.

PAZZUCCONI, F.; DELLA MURA, N.; SIRTORI, C. R. Soy protein diet supplementation reduces LDL cholesterol in severely hypercholesterolemic patients. Atherosclerosis, v. 135, n. 1001, p. 18, 1997.

RIPSIN, C. M. et al. Oat products and lipid lowering: a meta-analysis. JAMA, v. 267, n. 24, p. 3317, 1992.

ROMERO, A. L. et al. Cookies enriched with psyllium or oat bran lower plasma LDL cholesterol in normal and hypercholesterolemic men from Northerm Mexico. Journal of the American College of Nutrition, v. 17, n. 6, p. 601-608, 1998.

STATISTICA for windows V. 5.0. Software, v.II. Tulsa: Statsoft, 1995.

SUDHA, M. L.; VETRIMANI, R.; LEELAVATHI, K. Influence of fibre from different cereals on the rheological characteristics of wheat flour dough and on biscuit quality. Food Chemistry, v. 100, n. 4, p. 1365-1370, 2007.

UYSAL, H. et al. Effect of dietary fibre and xylanase enzyme addition on the selected properties of wire-cut cookies. Journal of Food Engineering, v. 78, n. 3, p. 1074-1078, 2007.

WONG, W. W. et al. Cholesterol-lowering effect of soy protein in normocholesterolemic and hypercholesterolemic men. American Journal of Clinical Nutrition, v. 68, n. 6 p. 1385S-1389S, 1998. Suplemento. 